\title{
HOW TO REDUCE ACCEPTED ESTIMATED BLOOD LOSS (EBL) IN CAESAREAN DELIVERY- CONVENTIONAL VS. WITH MODIFICATIONS
}

\author{
Sarbeswar Mandal', Rahul Deb Mandal², Sumanta Kumar Mondal ${ }^{3}$
}

${ }_{1}^{1}$ Assistant Professor, Department of Obstetrics and Gynaecology, IPGME and R, Kolkata, West Bengal, India.

${ }^{2}$ Assistant Professor, Department of Obstetrics and Gynaecology, IPGME and R, Kolkata, West Bengal, India.

${ }^{3}$ Assistant Professor, Department of Obstetrics and Gynaecology, IPGME and R, Kolkata, West Bengal, India.

\section{ABSTRACT}

\section{BACKGROUND}

In every caesarean delivery, blood vessels are cut as the surgeon opens the wall of the uterus to gain access to the baby. By modifications in some steps (five steps of modification), we reduced accepted estimated blood loss (EBL) even below normal with minimal complications in caesarean section.

The aim of this study is to compare the Estimated Blood Loss (EBL) in two methods of LSCS (Lower Segment Caesarean Section).

\section{MATERIALS AND METHODS}

In the Department of Obstetrics and Gynaecology, IPGME and R/ SSKM Hospital, West Bengal, India, 340 women were assessed and planned for caesarean delivery. They were categorised into Group A (Modification) and Group B (Conventional) with allocation of equal numbers in each group.

\section{RESULTS}

The results of individual groups (Gr- A and Gr- B) were tabulated and analysed for statistical significance and it has been observed that with modifications (Gr- A) had minimised blood loss, even less than accepted ( $p$-value $<0.005$ ), without any adverse effects to the health of mother and the baby.

\section{CONCLUSION}

Modifications in some steps during caesarean delivery leads to less blood loss; so these modifications should be incorporated or practiced regularly if required. Health personnel should be trained about it.

\section{KEY WORDS}

Caesarean Delivery, Five Points Modification, Less Blood, Maternal, Mortality, Morbidity.

HOW TO CITE THIS ARTICLE: Mandal S, Mandal RD, Mondal SK. How to reduce accepted estimated blood loss (EBL) in caesarean delivery- conventional vs. with modifications. J. Evolution Med. Dent. Sci. 2018;7(28):3174-3177, DOI: 10.14260/jemds/2018/714

\section{BACKGROUND}

The Estimated Blood Loss (EBL) during uncomplicated vaginal and caesarean delivery is about $500 \mathrm{~mL}$ and $1000 \mathrm{~mL}$ respectively, which are informatively considered as normal loss. As per Global WHO survey reports there are gradually increased caesarean delivery ratio, considering its safety even after taking different technical alternation in surgical steps (Joel-Cohen based method) and with administration of oxytocics still there is no significant change in blood loss during caesarean delivery. In this study by modifications in some steps which are of low cost, easy to perform, easily available and not harmful minimises Estimated Blood Loss (EBL) even below normal in such low haemoglobin containing mothers of developing countries like India for meaningful reduction of post-partum anaemia, blood transfusion and morbidity and mortality.

'Financial or Other Competing Interest': None.

Submission 17-05-2018, Peer Review 24-06-2018,

Acceptance 01-07-2018, Published 09-07-2018.

Corresponding Author:

Dr. Sumanta Kumar Mondal,

Vivekananda Apartment,

Block-A, Flat No. A1,

$62 / 1 B$, Vivekananda Sarani,

Kolkata-700078, West Bengal, India.

E-mail: skmondal1979@gmail.com

DOI: $10.14260 /$ jemds $/ 2018 / 714$

\section{(c) $(\mathbf{5})$}

\section{Aim}

To compare the Estimated Blood Loss (EBL) in two methods of LSCS (Lower Segment Caesarean Section).

\section{MATERIALS AND METHODS}

The study was conducted in the Department of Gynaecology and Obstetrics, IPGME and R, Kolkata, West Bengal, India from 01.02.2011 to 31.01.2012 after approval from Institutional Ethical Review Board.

\section{Study Design}

A prospective clinical, Institutional, randomised, controlled trial. The sample size taken for the study was 340 . Since the calculated sample size was too high and thereby not feasible to include in this limited period of study, we had to limit the sample size for convenience. [Total sample- 340, 170 in each group, Gr A and Gr B].

Allocation of cases were done as per inclusion and exclusion criteria on random basis and allocation was done before surgery by Sequentially Numbered Opaque Sealed Envelopes (SNOSE). Sequence were generated in the envelope by a computerised random number generator. The envelopes were same in size and shape, same weight mentioning the code- $\mathrm{C}$ (for conventional) and code- $\mathrm{M}$ (for modification) within it. Aluminium foil inside the envelope was used to render the envelope impermeable to intense light. The envelopes are numbered in advance, opened sequentially only after the participant's name and other 
details are written on the appropriate envelope. We also make use of carbon paper inside the envelope, which transfers such information to the assigned allocation and thus creates a valuable audit trail. Patient names were registered in the registration book in OT before surgery. [The total numbers (340) of women were assessed, planned and categorically allotted equal numbers in each group ( $\mathrm{Gr} \mathrm{A}$ and Gr B)].

\section{Inclusion Criteria}

Caesarean Delivery done in each Group as follows-

1. Post caesarean pregnancy.

2. Foetal distress (CTG abnormal).

3. PIH and Eclampsia.

4. Post-dated with failed induction.

5. CPD with Dysfunctional labour.

6. Breech shoulder and transverse lie.

7. PROM with dribbling and CTG changes.

8. IUGR with CTG changes.

9. $\mathrm{APH}$.

10. Rh-negative pregnancy.

11. DM and heart disease.

12. Multiple pregnancy.

13. Elective.

\section{Exclusion Criteria}

1. Drug allergy.

2. Classical caesarean and other type of scars.

\section{METHODOLOGY}

The modification during Caesarean delivery are done in Group A in "FIVE STEPS" as below-

1. Sublingual Misoprostol $(600 \mu \mathrm{g})$ administration after spinal anaesthesia, preferably after catheterisation but baby must be delivered within 10 minutes of application.

2. Electrosurgical unit used except for skin incision as per recommendation.

3. Packing of uterine cavity by sterile moistened laparotomy mops after expulsion of placenta, membrane and cleansing the cavity.

4. Angles of uterine incision, individual vessels and sinuses are secured separately by either ligature or cautery.

5. Single-layer running lock closure of transverse uterine incision; mops must be removed before completion of closure. The estimated blood loss is measured by-

a. Visual clot size of cleansed fist- about $500 \mathrm{~mL}$.

b. Swabs/ mops weighing 1 gram $=1 \mathrm{~mL}$ (Difference between wet mops minus dry mops).

c. Estimation of haemoglobin and haematocrit (preand post-operative).

The blood samples from both groups (Group A and Group B) duly collected before starting operation in OT table and again before shifting from OT table after completion of operation for estimation of haemoglobin and haematocrit. The conventional method used is considered as Group B.

\section{Statistical Method Used}

Data analysed by using GraphPad Prism version 5, p-value $\leq$ 0.05 was considered for statistical significance. P-value $\leq$ 0.001 was considered for highly statistical significance.

Test- Fisher's exact test and unpaired t-test.

\section{RESULTS}

The results of individual groups are estimated, and outcomes are analysed in the form of primary outcome and secondary outcome [Short term- mother and baby and secondary outcome on long-term basis shown in table (Table 1)].

\begin{tabular}{|c|c|c|c|}
\hline Indicators & $\begin{array}{l}\text { Group A } \\
(\mathrm{N}=170)\end{array}$ & $\begin{array}{l}\text { Group B } \\
(\mathrm{N}=170)\end{array}$ & $\begin{array}{c}\text { P-value } \\
\text { (Fisher's Exact } \\
\text { Test, Unpaired T- } \\
\text { Test) }\end{array}$ \\
\hline $\begin{array}{l}\text { Blood Loss } \\
\text { Hb\% drop } \\
\text { PCV drop } \\
\text { Mops weight }\end{array}$ & $\begin{array}{l}0.4 \pm 0.05 \\
1.8 \pm 0.02 \\
425 \pm 115\end{array}$ & $\begin{array}{l}0.9 \pm 0.05 \\
2.7 \pm 0.10 \\
775 \pm 175\end{array}$ & $\begin{array}{c}\text { (Unpaired t-test) } \\
\mathrm{p}=0.0039 \\
\mathrm{p}<0.0001 \\
\mathrm{p}<0.0001\end{array}$ \\
\hline $\begin{array}{l}\text { Transfusion } \\
\text { required } \\
\text { Blood } \\
\text { transfusion } \\
\text { Volume } \\
\text { expander }\end{array}$ & $\begin{array}{l}3(1.76 \%) \\
10(5.88 \%)\end{array}$ & $\begin{array}{c}17(10 \%) \\
40(23.5 \%)\end{array}$ & $\begin{array}{l}\mathrm{p}=0.0019 \\
\mathrm{p}<0.0001\end{array}$ \\
\hline $\begin{array}{l}\text { Organ failure } \\
\text { with } \\
\text { ICCU care and } \\
\text { death }\end{array}$ & $4(2.35 \%)$ & $\begin{array}{c}19(11.1 \%) \\
\text { with } \\
2(1.17 \%) \\
\text { cases ICCU } \\
\text { transfer }\end{array}$ & $p=0.0021$ \\
\hline
\end{tabular}

Table 1 shows so far blood loss, transfusion requirement and organ failure. ICCU care and death concerning all were significantly low in Group A compared to Group B (p value < 0.05).

\begin{tabular}{|c|c|c|c|}
\hline \multicolumn{4}{|l|}{ Mother } \\
\hline Indicators & $\begin{array}{l}\text { Group A } \\
(\mathrm{N}=170)\end{array}$ & $\begin{array}{l}\text { Group B } \\
(N=170)\end{array}$ & \begin{tabular}{|c|} 
P-value \\
(Unpaired T- \\
Test, Fisher's \\
Exact Test) \\
\end{tabular} \\
\hline $\begin{array}{l}\text { Operation } \\
\text { time }\end{array}$ & $\begin{array}{c}45-60 \text { mins } \\
\text { Mean- } 48.47 \text {, } \\
\text { SD- } 4.12\end{array}$ & $\begin{array}{c}55-60 \text { mins } \\
\text { Mean- } 55.29 \\
\text { SD- } 2.72\end{array}$ & $\mathrm{p}<0.0001$ \\
\hline $\begin{array}{l}\text { Mobilisation } \\
\text { time }\end{array}$ & $\begin{array}{c}<12 \text { hrs. } \\
\text { Mean- } 8.76 \text {, } \\
\text { SD- } 1.26\end{array}$ & \begin{tabular}{|c|}
$>12$ hrs. \\
Mean- 15.05, \\
SD- 1.83 \\
\end{tabular} & $\mathrm{p}<0.0001$ \\
\hline $\begin{array}{l}\text { Oral feeding } \\
\text { time }\end{array}$ & $\begin{array}{c}<12 \text { hrs. } \\
\text { Mean- } 8.7, \\
\text { SD- } 1.2 \\
\end{array}$ & \begin{tabular}{|c|}
$>12$ hrs. \\
Mean- 15.058, \\
SD- 1.835 \\
\end{tabular} & $\mathrm{p}<0.0001$ \\
\hline $\begin{array}{c}\text { Pyrexia and } \\
\text { loose motion }\end{array}$ & $10(5.88 \%)$ & $15(8.82 \%)$ & $p=0.4064$ \\
\hline
\end{tabular}

Table 2 shows so far operation time, mobilisation time and oral feeding time concerning all were significantly low in Group A compared to Group B (P-value < 0.05).

\begin{tabular}{|c|c|c|c|}
\hline Indicators & $\begin{array}{c}\text { Group A } \\
(\mathbf{N = 1 7 0 )}\end{array}$ & $\begin{array}{c}\text { Group B } \\
(\mathbf{N}=170)\end{array}$ & $\begin{array}{c}\text { P-value (Fisher's } \\
\text { Exact Test, } \\
\text { Unpaired T-Test) }\end{array}$ \\
\hline $\begin{array}{c}\text { APGAR } \\
\text { score } \\
7-10 \\
4-6\end{array}$ & $\begin{array}{c}140(82.4 \%) \\
30(17.6 \%)\end{array}$ & $\begin{array}{c}122(71.8 \%) \\
48(28.2 \%)\end{array}$ & $\begin{array}{c}\mathrm{p}=0.0265 \\
\mathrm{p}=0.0279\end{array}$ \\
\hline $\begin{array}{c}\text { Meconium } \\
\text { stained }\end{array}$ & $10(5.88 \%)$ & $23(13.52 \%)$ & $\mathrm{p}=0.0267$ \\
\hline $\begin{array}{c}\text { Delivery } \\
\text { time }\end{array}$ & $\begin{array}{c}\text { Mean- } 7.764 \\
\text { SD- } 1.11\end{array}$ & $\begin{array}{c}\text { Mean- } 12.64 \\
\text { SD- } 1.53\end{array}$ & $\mathrm{p}<0.0001$ \\
\hline
\end{tabular}




\begin{tabular}{|c|c|c|c|}
\hline Birth trauma & $2(1.17 \%)$ & $9(5.29 \%)$ & $\mathrm{p}=0.0612$ \\
\hline $\begin{array}{c}\text { NICU } \\
\text { admission }\end{array}$ & $18(10.58 \%)$ & $35(20.58 \%)$ & $\mathrm{p}=0.0162$ \\
\hline $\begin{array}{c}\text { Birth } \\
\text { weight }\end{array}$ & $22(12.94 \%)$ & $13(7.64 \%)$ & \\
$<1.5 \mathrm{~kg}$ & $30(17.64 \%)$ & $32(18.82 \%)$ & $\mathrm{p}=0.9134$ \\
$1.5-2 \mathrm{~kg}$ & $40(23.52 \%)$ & $47(27.64 \%)$ & \\
$2-2.5 \mathrm{~kg}$ & $78(45.9)$ & $78(45.9 \%)$ & \\
$>2.5 \mathrm{~kg}$ & \multicolumn{4}{|c|}{ Table 3. Baby } \\
\hline
\end{tabular}

Table 3 shows so far APGAR score concerning Group A (case) shows better APGAR score, meconium stained, and delivery time were all significantly low in Group A compared to Group B (P value < 0.05).

\begin{tabular}{|c|c|c|c|}
\hline Indicators & $\begin{array}{c}\text { Group A } \\
\text { (N=170) }\end{array}$ & $\begin{array}{c}\text { Group B } \\
\text { (N=170) }\end{array}$ & $\begin{array}{c}\text { P-value } \\
\text { (Fisher's } \\
\text { Exact Test) }\end{array}$ \\
\hline $\begin{array}{c}\text { Wound } \\
\text { complications }\end{array}$ & $\begin{array}{c}7(4.11 \%) \\
\text { [cured by } \\
\text { dressing] }\end{array}$ & $\begin{array}{c}25(14.7 \%) \\
\text { 7 (4.11\%) cases } \\
\text { required } \\
\text { secondary suture }]\end{array}$ & $\mathrm{p}=0.0013$ \\
\hline $\begin{array}{c}\text { Pain and } \\
\text { hardness }\end{array}$ & $10(5.88 \%)$ & $26(15.29 \%)$ & $\mathrm{p}=0.0026$ \\
\hline \multicolumn{4}{|c|}{ Table 4. Long-Term Outcome of Mother } \\
\hline
\end{tabular}

Table 4 show wound complication and pain, hardness was significantly low in Group A compared to Group B (pvalue $<0.05$ ).

\begin{tabular}{|c|c|c|c|}
\hline Indicators & $\begin{array}{c}\text { Group A } \\
\mathbf{( N = 1 7 0 )}\end{array}$ & $\begin{array}{c}\text { Group B } \\
\mathbf{( N = 1 7 0 )}\end{array}$ & $\begin{array}{c}\text { P-value } \\
\text { (Fisher's Exact } \\
\text { Test, Unpaired } \\
\text { T-Test) }\end{array}$ \\
\hline $\begin{array}{c}\text { Hospital stay } \\
\text { (Mother and } \\
\text { Baby) }\end{array}$ & $\begin{array}{c}<\text { Mean-5.294, } \\
\text { SD-0.667 }\end{array}$ & $\begin{array}{c}>7 \text { days } \\
\text { Sean-8.70, } \\
\text { SD-0.894 }\end{array}$ & $\begin{array}{c}\mathrm{p}<0.0001 \\
\text { (Fisher's Exact } \\
\text { Test) }\end{array}$ \\
\hline $\begin{array}{c}\text { Re-admission } \\
\text { (Mother and } \\
\text { Baby) }\end{array}$ & $2(1.17 \%)$ & $8(4.7 \%)$ & $\begin{array}{c}\mathrm{p}=0.1042 \\
\text { (Unpaired T- } \\
\text { Test) }\end{array}$ \\
\hline \multicolumn{3}{|c|}{ Table 5. Health Services Used } \\
\hline
\end{tabular}

Table 5 show hospital stay (Mother and Baby) were significantly low in Group A compared to Group B (P value $<0.05)$.

\section{DISCUSSION}

The adverse effects are mostly dose dependent and are seen maximum in a dose of $800 \mu \mathrm{g}$ of misoprostol, though hyperstimulation and hypotension are commonly observed in pregnant women without significant neonatal compromise. ${ }^{1}$

The recent study shows buccal misoprostol reduces the dose of additional uterotonic during caesarean delivery. ${ }^{2}$ No data indicates using electrosurgical unit in pregnancy has any adverse effect to foetus.

During caesarean delivery, the only concern is accidental touch to the baby which does not mean that the usual technique of making incision in uterus would preclude using electrosurgical incision.

After making skin incision, lacerated vessels, vessels between muscle and facia and if muscle cutting required electrocautery is the best.
After securing, coagulation through blunt and sharp extension of the uterine incision are equally safe.(3,4) We hereby extend incision by electrosurgical unit.

Packing of uterine cavity by moistened sterile laparotomy pack after expression of placenta with membranes and after cleansing the cavity, because uterine packing successfully arrested haemorrhage. 5

Most of the complications during and after operation, especially blood loss and haemoperitoneum occur due to improper secure of angles and individual bleeding points. That is why we have secured angles of uterine incisions and bleeding sinuses separately.

A continuous running lock suture requiring few additional haemostatic sutures and less operation time without any short-term detrimental effects with follow-up does not significantly affect maternal and foetal complications in next pregnancy,(6) even uterine rupture in trial of labour.(7)

In our study primary outcome shows statistically less blood loss required, less blood transfusions and less ICCU care compared to conventional methods. Secondary outcome of baby and mothers of modified methods are always better than the control groups.

The drawback of this study are fertility problems, complications in future pregnancy and surgery are not analysed.

\section{Summary}

Modifications in some steps which are of low cost, easy to perform, easily available and not harmful minimises Estimated Blood Loss (EBL) even below normal in developing countries like India for reduction of post-partum anaemia, need of blood transfusion and reduction of morbidity and mortality.

In our study, it showed the similar result with statistical significance $(\mathrm{p}<0.05$, Table 1$)$.

\section{CONCLUSION}

As per global WHO survey reports, there are gradually increasing caesarean delivery rates (in our Institution caesarean delivery is more than vaginal delivery) and we should consider its safety and security with minimised complications. By modifying some steps, (five steps of modification) accepted estimated blood loss (EBL) was reduced, even below normal with minimal complications. These modifications should be incorporated in standard caesarean delivery techniques with adequate training to health personnel to minimise maternal and perinatal morbidity and mortality.

\section{ACKNOWLEDGEMENT}

We are thankful to the Department of Gynaecology and Obstetrics and our Institution (IPGME and R, Kolkata) for giving permission to conduct the study.

\section{REFERENCES}

[1] Kotsonis FN, Dodd DC, Regnier B, et al. Preclinical toxicology profile of misoprostol. Dig Dis Sci 1985;30(11 Suppl):142S-6S. 
[2] Hamm J, Russell Z, Botha T, et al. Buccal misoprostol to prevent haemorrhage at caesarean delivery: randomised study. Am J Obstet Gynaecology 2005;192(5):1404-6.

[3] Rodriguez AL, Porter KB, O'Brien WF. Blunt versus sharp expansion of uterine incision in lower segment transverse caesarean section. AM J Obstet Gynecol 1994;171(4):1022-5.

[4] Magann EF, Chauhan SP, Bufkin L, et al. Intraoperative haemorrhage by blunt and sharp expansion of uterine incision in caesarean section delivery: a randomized control trial. Br J Obstet Gynecol 2002;109(4):448-52.
[5] Druzin ML. Packing of lower uterine segment for control of post-cesarean bleeding in instances placenta previa. Surg Gynecol Obstet 1989;169(6):543-5.

[6] Bjorklund K, Kimaro M, Urassa E, et al. Introduction of the Misgav-Ladach caesarean section at an African tertiary centre: a randomised controlled trial. BJOG 2000;107(2):209-16.

[7] Tucker JM, Hauth JC, Hodgkins P, et al. Trial of labor after a one-or two-layer closure of low transverse uterine incision. Am J Obstet Gynecol 1993;168(2):545-6. 